\title{
BULLYING NAS ESCOLAS E SUAS CONSEQUÊNCIAS
}

\section{ARTIGO DE REVISÃo}

GIULIATO, Mauro Volney ${ }^{1}$

GIULIATO, Mauro Volney. Bullying nas escolas e suas consequências. Revista Científica Multidisciplinar Núcleo do Conhecimento. Ano 05, Ed. 11, Vol. 08, pp. 84102. Novembro de 2020. ISSN: 2448-0959, Link de acesso: https://www.nucleodoconhecimento.com.br/educacao/bullying-nas-escolas

\section{RESUMO}

Este texto tem como objetivo investigar a questão do bullying nas escolas brasileiras e suas consequências. Para isso, por meio de estratégias metodológicas relacionadas à pesquisa qualitativa interpretativa, de cunho descritivo bibliográfico, discutiu-se, a partir de referenciais teóricos da área da educação, psicologia e dos documentos que regem a educação básica, a função da escola e da família enquanto promotora da formação acadêmica e sua participação na evolução das competências socioemocionais dos indivíduos. As articulações teóricas aqui realizadas permitiram a identificação de alguns pontos importantes relacionados ao bullying sofrido e praticado nas escolas. Dentre tais pontos, pode-se citar as principais práticas: exclusão pelos colegas; piadas; ameaças; agressões físicas, materiais e psicológicas; dentre outras práticas. Além disso, os pontos elencados permitem inferir a respeito da importância do desenvolvimento das competências socioemocionais no processo de formação dos estudantes, principalmente os da Educação Básica, que são as principais vítimas de bullying nas escolas. Além disso, a instituição familiar também tem uma importante função na prevenção do bullying nas escolas.

Palavras-chave: Educação, escola, bullying, intimidação sistemática.

${ }^{1}$ Mestrado em educação com graduação em psicologia. 


\section{INTRODUÇÃO}

A rápida e constante evolução da sociedade tem possibilitado uma verdadeira transformação em muitos aspectos do cotidiano. Santaella (2008) exemplifica que tais transformações vão desde a substituição do despertador a corda pela programação de horário nos smartphones até construção de carros que se movimentam de um ponto a outro da cidade sem motorista, apenas por comandos via satélite.

Tal desenvolvimento tem se refletido em mudanças nas diferentes dimensões da sociedade: política, social, familiar, educacional, cultural, religiosa, dentre tantas outras.

No entanto, tais transformações não resultam apenas em aspectos positivos. Dentre os pontos negativos relacionados ao desenvolvimento da sociedade, pode-se destacar a violência.

Como destaca Fante (2005) a violência é evidenciada sempre que um determinado ato tem como consequência o constrangimento físico ou moral de outro indivíduo e ela está presente em todos os ambientes da sociedade, incluindo o ambiente escolar.

Ainda segundo Fante (2005) a violência, nos diferentes níveis de escolaridade, tem aumentado nas últimas décadas e é evidenciada em comportamentos agressivos advindos dos estudantes, como agressões físicas (por exemplo bater, chutar, tomar pertences) e verbais (apelidar de maneira pejorativa e discriminatória, insultar e constranger).

Tais comportamentos violentos no ambiente escolar têm chamado atenção de pesquisas recentes que os têm explorado academicamente por meio de um fenômeno chamado bullying (FANTE, 2005; TREVISOL; CAMPOS, 2016).

O presente trabalho visa investigar a questão do bullying nas escolas brasileiras e suas consequências. 
Para isso, decidiu-se, inicialmente, realizar uma discussão a respeito do bullying enquanto um problema crônico nas escolas, e com graves consequências, tanto para vítimas, quanto para os agressores, para isso, serão utilizadas como fonte de dados pesquisas desenvolvidas na área de psicologia e pedagogia que já estejam aceitas pela comunidade acadêmica destas áreas.

Além disso, objetivando uma análise específica sobre as consequências, algumas discussões relacionadas aos índices de depressão, ideação suicida e suicídio infantojuvenil também serão trazidas à baila.

\section{PROCEDIMENTOS METODOLÓGICOS}

Para o direcionamento deste texto foi utilizada uma metodologia de pesquisa de natureza qualitativa, de cunho bibliográfico, a fim de garantir a viabilidade das análises dos dados e das discussões dela resultante.

Para Gil (2008, p.44) "[...] a pesquisa bibliográfica é desenvolvida com base em material já elaborado, constituído principalmente de livros e artigos científicos", no caso deste texto, será utilizado como fonte de dados pesquisas acadêmicas relacionadas ao tema aqui proposto.

Ainda segundo o autor, a maioria dos estudos exige algum tipo de trabalho dessa natureza, como em casos de pesquisas desenvolvidas exclusivamente a partir de materiais bibliográficos, sendo que uma boa parte dos estudos de natureza exploratória pode ser definida como pesquisas bibliográficas.

Ainda sobre a pesquisa qualitativa, Devechi e Trevisan (2010, p. 150) ressaltam que estas

[...] aparecem para dar conta do lado não perceptível e não captável apenas por equações, médias e estatísticas [...] as pesquisas qualitativas surgem, portanto, como forma de evitar o tecnicismo e o reducionismo lógico-formal nas investigações educacionais em favor da recuperação da subjetividade. O diferencial das pesquisas qualitativas está relacionado com a inclusão da subjetividade; não é possível pensálas sem a participação do sujeito. 
Para Gil (2008) a pesquisa pode ser definida como um procedimento sistemático e racional que tem como objetivo apresentar respostas aos problemas que são propostos. Fazendo-se necessária quando não dispomos de informações suficientes para responder ao problema ou, quando disponível, essas informações se encontram em total desordem, não sendo possível com isso relacioná-las adequadamente ao problema.

Para Lakatos e Marconi (2003) a pesquisa é o meio pelo qual investigamos e averiguamos informações com objetivo de buscar dados com aplicações, com todo cuidado e rigor, que demanda o embasamento teórico e científico. O pesquisador é norteado por uma metodologia que direciona a sua pesquisa, seja por meio de leituras, análises, hipóteses, investigações, dentre outras.

Para Gil (2008, p. 42) pesquisa é "o processo formal e sistemático de desenvolvimento do Método científico e visa à produção de conhecimento novo".

Na Figura 1 são apresentados de forma sistemática os aspectos metodológicos adotados neste texto.

Figura 1: Aspectos metodológicos da pesquisa 


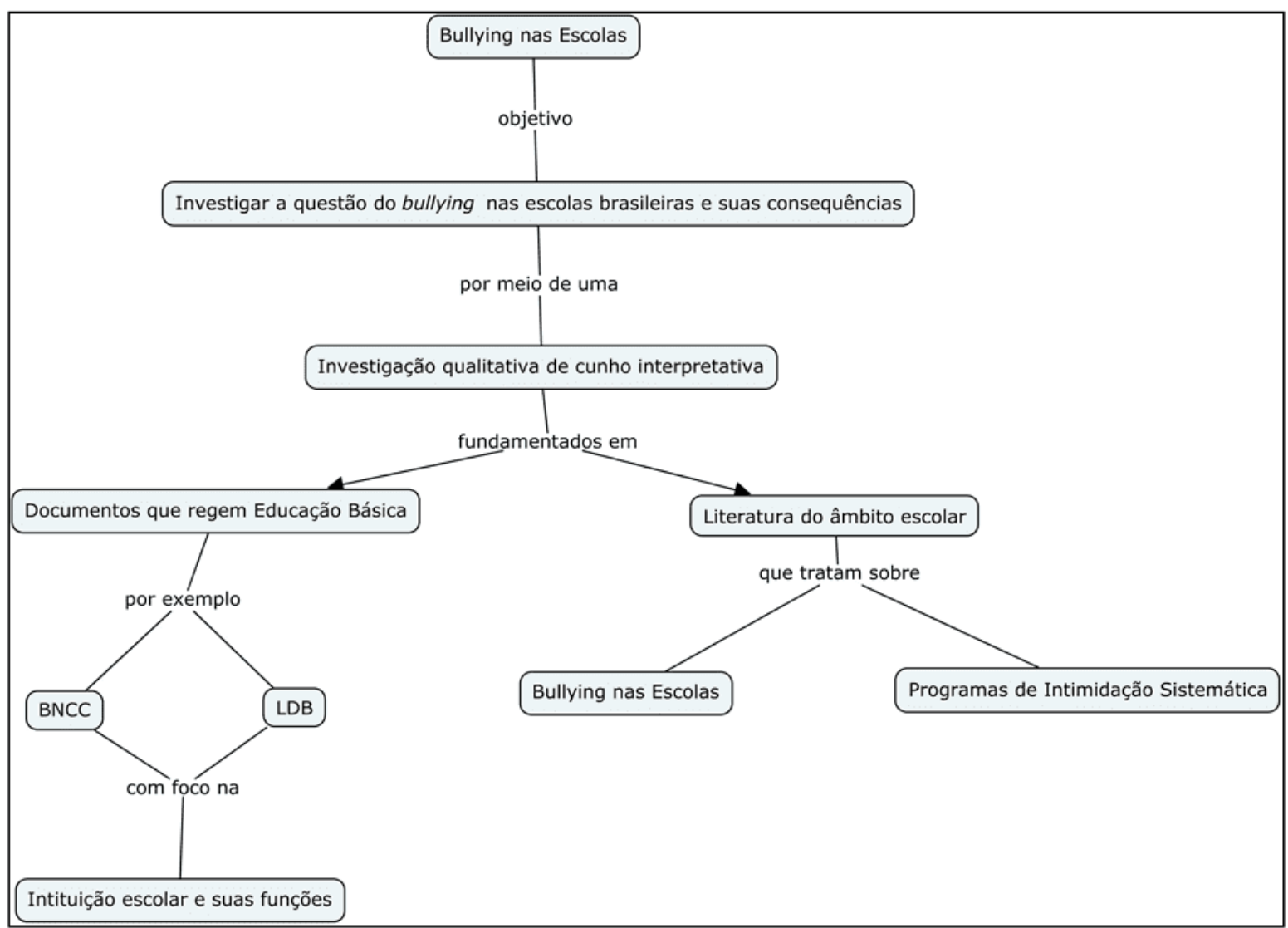

Fonte: O Autor (2020)

É com este caminhar metodológico que se deu o desenvolvimento deste texto.

\section{BULLYING NAS ESCOLAS: UM PROBLEMA QUE TRANSCENDE A} SALA DE AULA

A palavra bullying possui origem inglesa, sendo uma variação do termo bully que significa "valentão" e é utilizada para dar nome "ao desejo consciente e deliberado de maltratar outra pessoa e colocá-la sob tensão" (FANTE; PEDRA, 2008, p. 41).

Avilés Martínez (2006, p. 82) define o termo bullying como "[...] a prática que envolve, repetidamente, e mantida no tempo, a intimidação e o maltrato entre escolares, com o intuito de humilhar e submeter de forma abusiva uma vítima indefesa, sempre longe de supervisão adulta". 
Além disso, o bullying "[...] acarreta sofrimento psíquico, diminuição da autoestima, isolamento, prejuízos no aprendizado e no desempenho acadêmico" (MOURA; CRUZ; QUEVEDO, 2011, p. 27).

Vitimização, agressividade, violência entre pares e intimidação sistemática são termos, em português, utilizados para fazer referência ao bullying.

Estudando detalhadamente as causas do bullying nas escolas, Trevisol e Campos (2016) destacam alguns fatores que são fundamentais para a ocorrência de tais situações, dentre elas está a convivência familiar do educando.

Sobre a convivência familiar, especificamente, é importante ressaltar que as relações afetivas e sociais dos seres humanos estão em constante desenvolvimento a medida em que estes interagem entre si. Posto isto, é claro inferir que a família é uma entidade fundamental para a formação integral do indivíduo impactando, diretamente, no comportamento que este indivíduo demonstra quando está se relacionando com seus grupos sociais.

Com relação ao conceito de família, Castro (2000, p. 205) define-a como uma "célula máter da sociedade", uma vez que ela tem impacto tanto no desenvolvimento biológico quanto social do sujeito.

Ainda no que diz respeito à família, e à formação do sujeito em seu núcleo familiar, Ariés (1981) afirma que somente a partir do século XVIII a criança passou a ser vista na sociedade como um indivíduo cuja imagem devesse ser preservada e que, toda sua formação nesta fase da vida impactaria diretamente o cidadão que se formaria futuramente.

Ainda para Ariès (1981, p.160) "esse fenômeno comprova uma transformação considerável da família: esta se concentrou na criança, e sua vida confundiu-se com as relações cada vez mais sentimentais dos pais e dos filhos".

Assim, a família passa a ter um papel afetivo na formação do sujeito, no caso criança, enfatizando ainda a educação como um aspecto importante nas relações 
estabelecidas, considerando que, até então, a instituição escolar era inexistente e as crianças eram cientificamente educadas por meio de seus familiares.

Além disso, é importante frisar que, legalmente, mesmo com o papel bem definido da instituição escolar, a família desempenha um papel fundamental no desenvolvimento social do sujeito, uma vez que a família é a principal transmissora dos princípios e valores que nortearão o comportamento desse cidadão no presente e no futuro.

Além da convivência familiar, o preconceito e a crítica ao diferente, existente em sala de aula, também são, segundo Trevisol e Campos (2016), fatores que levam à ocorrência do bullying, assim como a falta de diálogo entre os estudantes.

Avilés Martínez (2006) define o preconceito como uma opinião que os sujeitos formam das pessoas antes mesmo de efetivamente conhecê-las. Trata-se de "[...] um julgamento apressado, superficial e muito perigoso, pois ao invés de melhorar a vida da sociedade, traz muitas situações complicadas e até mesmo violentas" (ÁVILES MARTÍNEZ, 2006, p. 27).

Ainda segundo o autor supracitado, dentre os preconceitos mais recorrentes dentro da escola, principalmente no que diz respeito à Educação Básica, são o racismo e a discriminação (sexual, religiosa e social).

O racismo acontece quando um indivíduo acredita que existem raças superiores às outras, sendo a raça definida por aspectos fenotípicos dos indivíduos, como a cor da pele, o formato do nariz, o tipo de cabelo, o tipo de sangue, o formato e a cor dos olhos, espessura dos lábios, dentre outros aspectos (TREVISOL; CAMPOS, 2016).

A discriminação, por sua vez, é a dificuldade que alguns indivíduos possuem em aceitar e conviver com as diferenças e, por vezes, as atitudes de tais indivíduos "[...] chegam ao delírio e, como são medrosos e inseguros, projetam sobre os outros que são inferiores a eles e que não podem ter os mesmos direitos", tratando os que eles julgam como inferiores a ele de maneira discriminatória (TREVISOL; CAMPOS, 2016, p. 28). 
Outros fatores também são destacados pelas pesquisas, como: o uso de drogas e outros vícios; a má influência dos meios de comunicação; o fato de o estudante ter sido alvo de violência (tanto familiar quanto entre os colegas), assim como a fragilidade emocional deste, pode ser a causa que o leve a praticar o bullying.

A intolerância e o individualismo, a má influência dos colegas e a má comunicação entre a família e a escola são ainda fatores que, de alguma maneira, são encaradas como fatores que potencializam a prática do bullying no ambiente escolar.

Sobre, especificamente, a instituição escolar, cabe ressaltar que uma comunidade escolar é composta por diferentes agentes: professores, estudantes, pais e responsáveis, pedagogos, supervisores, diretores, orientadores, psicólogos, inspetores, serviços gerais, dentre outros. Assim, uma gestão escolar articulada e comprometida com o processo de ensino e de aprendizagem é fundamental para o funcionamento adequado da escola e, no caso do bullying, todos esses agentes devem estar envolvidos nas ações que buscam preveni-lo.

No âmbito escolar, cabe ao diretor o compromisso de liderar e organizar o trabalho de todos os agentes envolvidos com a escola, de modo a

[...] orientá-los no desenvolvimento do ambiente educacional capaz de promover aprendizagens e formação dos alunos, no nível mais elevado possível, de modo que estejam capacitados a enfrentar os novos desafios que são apresentados, além de garantir que a civilidade seja predominante no ambiente escolar (LÜCK, 2009, p. 17).

É importante ressaltar que, ainda conforme a autora supracitada, a ação do diretor escolar estará limitada à sua concepção sobre educação, gestão escolar e seu papel profissional na liderança e organização da escola. Tudo isso impactará diretamente a gestão escolar local.

Uma gestão articulada visa, dentre outras coisas, o pleno funcionamento escolar como organização social, cujo foco está na formação integral dos estudantes, mesmo enquanto cidadãos, sempre fundamentando-se em princípios e diretrizes educacionais constantes nos documentos que regem a educação. 
Assim, todas as ações da escola, desde o estudo da grade horária e distribuição das aulas até a definição da metodologia de ensino ser adotada, têm o potencial de contribuírem e enriquecerem o processo de gestão.

Além destes, propiciar o desenvolvimento da autonomia dos professores e pedagogos também é uma ação do gestor que possibilita a busca e proposição de soluções para os problemas que afetam a qualidade do processo de ensino e aprendizagem na escola (CERVI, 2013).

Assim como o diretor escolar possui uma série de deveres relacionados à gestão, o professor também tem atribuições próprias. Dentre tais atribuições, é possível destacar a escolha de uma metodologia adequada; o levantamento e interpretação dos dados relativos à sua sala de aula; a preparação dos conteúdos a serem trabalhados; a elaboração de atividades; a avaliação dos estudantes; dentre tantas outras. Todas essas atribuições dos professores irão impactar diretamente o processo de formação do estudante, podendo estimular atitudes cidadãs éticas e morais.

Por meio de sua pedagogia crítica-social dos conteúdos, Saviani (2016) defende que professores e alunos vivenciam, especificamente, uma relação social de ensino, com a finalidade de estudarem os conhecimentos de contextos históricos antepassados, a fim de aprimorar e construir novas elaborações do conhecimento. No entanto, além disso, a formação cidadã dos estudantes também acaba sendo moldada por aquilo que acontece dentro da sala de aula.

Neste contexto, as práticas preparatórias dos alunos (Pedagogia Tradicional) e as atividades (Pedagogia Nova) não são consideradas como ponto inicial da ação pedagógica, mas sim a prática social comum entre professor e o aluno.

A respeito dessa prática social, Bulgraen (2010) ressalta que o professor precisa estar ciente de que a aplicabilidade de conteúdos atuais não são suficientes para suprir a necessidade de aprendizagem dos alunos, deste modo, deve-se resgatar os conhecimentos amplos e históricos, permitindo que os alunos interpretem suas experiências e suas aprendizagens na vida social. 
Neste contexto, identifica-se a importância das experiências sociais dos educandos, bem como o seu contexto social, para que os mesmos possam se considerar parte do ambiente escolar e, consequentemente, indivíduos ativos no processo de ensino e aprendizagem (ZIMER, 2008).

Ainda sobre as atribuições e deveres dos professores, como as citadas acima, é importante ressaltar que existem documentos que regem a educação, em todo e qualquer nível, cujas ações docentes devem estar em concordância. Exemplos desses documentos são os Parâmetros Nacionais Curriculares - PCN (BRASIL, 1998) e, mais recentemente, a Base Nacional Comum Curricular - BNCC (BRASIL, 2017).

Tais documentos apresentam diretrizes para o desenvolvimento do trabalho docente em sala de aula e, geralmente, são direcionados às diferentes etapas da escolarização (Educação Infantil; Ensino Fundamental; e Ensino Médio). Na sequência, serão apresentadas algumas considerações a respeito da BNCC e suas implicações para a gestão escolar.

\section{O PROGRAMA DE COMBATE À INTIMIDAÇÃO SISTEMÁTICA}

No dia 6 de novembro de 2016, foi ratificada no Brasil, pela então presidente da república Dilma Rousseff a Lei № 13.185, que fundou o Programa de Combate à Intimidação Sistemática

Esta lei, composta por oito artigos, fez da luta contra o bullying escolar uma política pública de educação e, ainda implementou um conjunto de ações voltadas a sua erradicação, através de campanhas publicitárias, capacitação dos profissionais da educação, com intuito de prepará-los para lidarem com casos de bullying, e realização de um diálogo mais estreito entre a escola e a família.

Segundo a lei supracitada, bullying é

[...] todo ato de violência física ou psicológica, intencional e repetitivo que ocorre sem motivação evidente, praticado por indivíduo ou grupo, contra uma ou mais pessoas, com o objetivo de intimidá-la ou agredi-la, 
causando dor e angústia à vítima, em uma relação de desequilíbrio de poder entre as partes envolvidas (BRASIL, 2015, Art. $1^{\circ}, \S 1^{\circ}$ ).

É importante ressaltar ainda que a referida legislação versa também sobre outra modalidade de agressão, abordada pelo texto como o cyberbullying, que acontece quando a violência e os ataques são feitos no meio virtual.

A fim de combater as práticas de bullying (e cyberbullying), desde a promulgação da Lei 13.185/2015, além de fazer campanhas educativas, as escolas devem promover ações de capacitação de professores e todos os demais agentes educacionais, além da comunidade em geral, sobre o assunto, possibilitando que todos os indivíduos estejam capacitados para lidar com situações que envolvam este tipo de agressão.

Vale ressaltar ainda que o Programa de Combate à Intimidação Sistemática vai além da violência praticada de alunos contra alunos, este programa combate ainda a discriminação promovida por professores ou funcionários das instituições escolares, tendo as escolas que prestar assistência psicológica, social e jurídica às vítimas.

Como já citado, dentre os objetivos do programa instituído pela Lei 13.185/2015 estão a capacitação de toda a equipe pedagógica, incluindo professores e demais agentes, para a implementação de ações de discussão, prevenção, orientação e solução do problema, assim como a orientação de pais e familiares para identificar vítimas e agressores.

Um exemplo de projeto criado a fim de atender ao disposto na legislação supracitada é o denominado "Unidos no Combate à Prática do Bullying - Jornal, Literatura, Comunidade e Cidadania", este é um projeto desenvolvido no estado de São Paulo em uma das escolas com o maior índice de denúncias de alunos relacionadas à prática de bullying.

Segundo publicação do Ministério da Ciência e da Educação, o projeto já havia sido desenvolvido nos anos de 2008 e 2009, mas só se efetivou a partir da promulgação da lei 13.185/2015, sendo um dos vencedores da quarta edição do Prêmio Professores do Brasil. 
O projeto atingiu, inicialmente, os alunos do primeiro ano do ensino fundamental da Escola Municipal Neil Fioravanti, integrando, posteriormente, toda a escola, as famílias dos estudantes e a comunidade.

Ainda neste sentido, em 14 de maio de 2018, o então Presidente da República Michel Temer sancionou um decreto de lei que incluiu, entre as atribuições das escolas, medidas de prevenção e combate a diversos tipos de violência, como o bullying, ratificando o disposto na lei de 2015.

A promulgação de 2018 alterou a Lei de Diretrizes e Bases da Educação Nacional (LDB - Lei 9.394/1996). A ideia da proposta, aprovada antes pelo Congresso Nacional, foi reforçar a Lei de Combate ao Bullying. Assim, reforça-se a obrigatoriedade de as instituições de ensino também terem a obrigação de promover a cultura de paz.

\section{O BULLYING E OS NÚMEROS DE SUAS CONSEQUÊNCIAS}

A depressão é uma doença que pode se apresentar em qualquer etapa da vida. Alguns estudos, como o de Costa (2011), Burochovith e Santos (2008) e Fonseca, Ferreira e Fonseca (2005) mostram que, de fato, existe uma alta prevalência de sintomas depressivos em crianças e adolescentes.

Burochovith e Santos (2008), inclusive, afirmam que esta prevalência está diretamente relacionada com o fato de, nestas etapas da vida (infância e adolescência), as pessoas passarem grande parte do seu dia nos ambientes escolares de alguma forma, sofrendo algum tipo de intimidação.

Sobre a depressão, Tenaglia (2008) descreve em sua pesquisa os principais sintomas que assolam os sujeitos que sofrem desta doença, a saber

[...] ansiedade, angústia, a irritabilidade e tristeza exagerada; perda de interesse nas atividades diárias; indecisão e desinteresses generalizados; sentimento de culpa e inutilidade; dificuldades de concentração; queixas físicas com dores inexplicáveis na cabeça, musculares, estômago, pressão no peito, dentre outras; Insônia ou hipersonia; alterações de apetite e peso para mais ou para menos e, 
ainda, sentimento suicida, planejar uma forma ou tentativa de suicídio (TENAGLIA, 2018, p. 28).

No Brasil, estima-se que um a cada dez alunos é vítima de bullying, de modo frequente, nas escolas, de acordo com os dados da Organização para a Cooperação e Desenvolvimento Econômico (OCDE) publicados em 2015.

Segundo o relatório da pesquisa citada acima, as vítimas de bullying são adolescentes que sofrem agressões físicas ou psicológicas, sendo alvo de piadas e boatos maldosos, excluídos propositalmente pelos colegas, que não são chamados para festas ou reuniões (BUROCHOVITH; SANTOS, 2008).

Ainda sobre o relatório da OCDE (2015), relatório este que faz parte do terceiro volume do Programa Internacional de Avaliação de Estudantes (PISA) é integralmente dedicado ao bem-estar dos estudantes, sendo baseado na resposta de mais de 540 mil estudantes de 15 anos de idade participantes da pesquisa que, por amostragem, representam 29 milhões de alunos de 72 países.

Os principais resultados da pesquisa são apresentados no Quadro 1.

Quadro 1: Resultados da Pesquisa sobre bullying da OCDE (2015)

\begin{tabular}{|l|l|}
\hline Percentual & Situação da qual é vítima \\
\hline $\mathbf{1 7 , 5} \%$ & Sofrem alguma forma de bullying algumas vezes por mês \\
\hline $\mathbf{7 , 8} \%$ & São excluídos pelos colegas \\
\hline $\mathbf{9 , 3} \%$ & São alvos de piadas \\
\hline $\mathbf{4 , 1} \%$ & São ameaçados \\
\hline $\mathbf{3 , 2} \%$ & São empurrados e agredidos fisicamente \\
\hline $\mathbf{5 , 3} \%$ & Colegas pegam e destroem suas coisas \\
\hline $\mathbf{7 , 9} \%$ & $\begin{array}{l}\text { São alvos de rumores maldosos } \\
\mathbf{9 \%} \%\end{array}$ \\
& $\begin{array}{l}\text { Foram classificados no estudo como vítimas frequentes de bullying } \\
\text { estando no topo do indicador de agressões e mais expostos a essa } \\
\text { situação. }\end{array}$ \\
\hline
\end{tabular}


Fonte: O Autor (2015)

É importante ressaltar que, em comparação com os outros países avaliados, à época, o Brasil aparece com um dos menores "índices de exposição ao bullying". Em um ranking de 53 países com os dados disponíveis, o Brasil localiza-se no 43ํl lugar (OCDE, 2015).

Assim, nos países da OCDE, cerca de 18,7\% dos estudantes relataram ser vítimas da ocorrência do bullying mais de uma vez por mês, enquanto $8,9 \%$ foram classificados como vítimas frequentes (idem).

De forma semelhante à pesquisa realizada em 2015 pela OCDE, Matos e Gonçalves (2019) investigaram estatisticamente os comportamentos de bullying sofridos e praticados na escola, conforme consta na Figura 2.

Figura 2: Aspectos metodológicos da pesquisa 


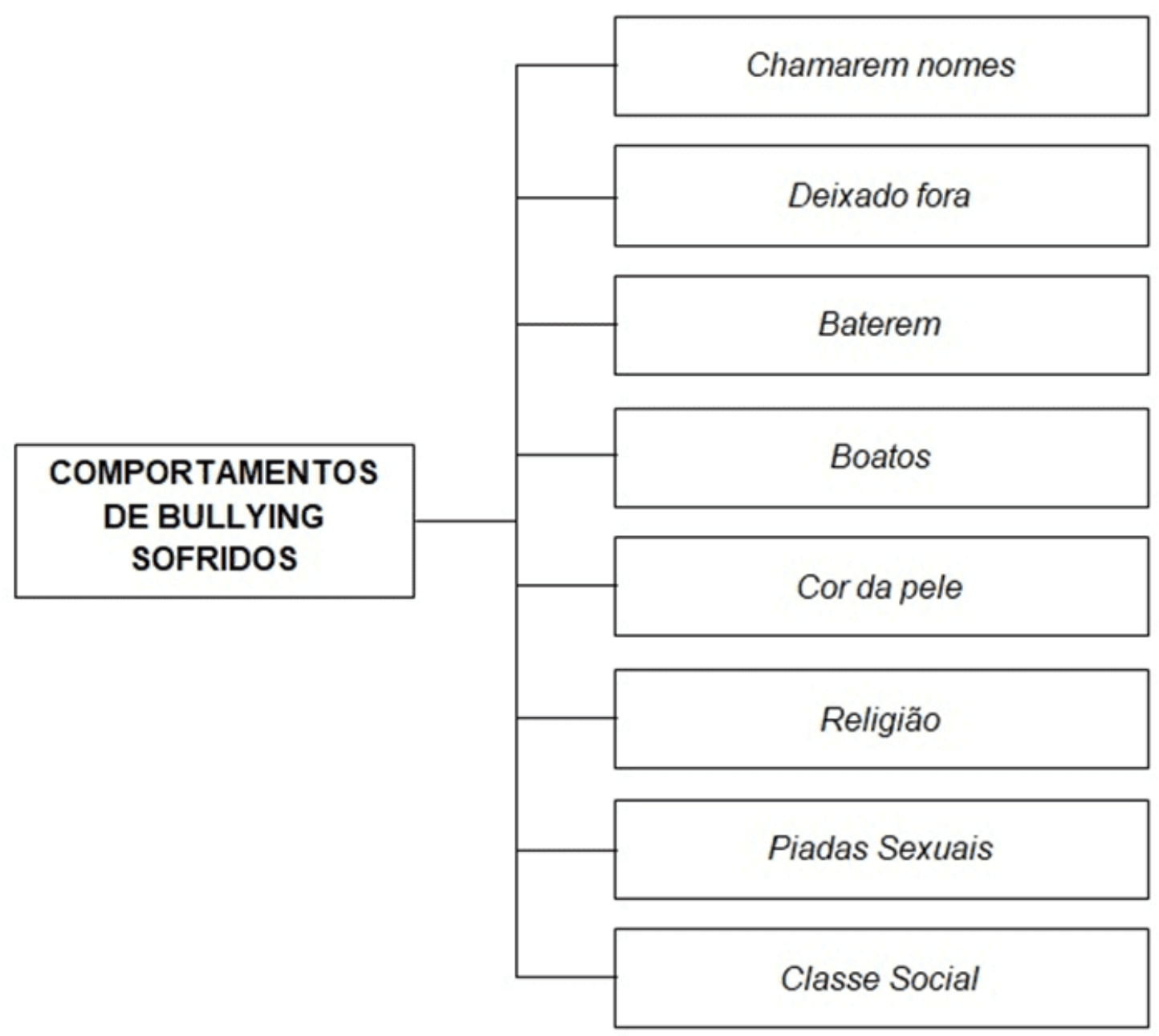

Fonte: Adaptado de Matos e Gonçalves (2019)

Conforme destacam Matos e Gonçalves (2019), o estudo dos autores buscou contribuir para o aprofundamento do conhecimento acerca desta problemática que é o bullying nas escolas, além de analisar a associação entre uma série de diferentes tipos de comportamentos de bullying, conforme consta na Figura 2 (chamar nomes, deixar de fora, bater, boatos, raça, religião, piadas sexuais e classe social) e algumas variáveis preditoras e comportamentais.

Dentre tais variáveis os autores destacam: o consumo de álcool, drogas e porte de armas; e variáveis cognitivas relacionadas à percepção de satisfação com a vida $\mathrm{e}$ percepção de segurança na escola. 
É importante ressaltar que os estudantes se sentem provocados e dizem provocar de diferentes formas, sendo eles afirmam ser provocados e provocar com mais frequência por meio de insultos verbais, boatos e piadas sexuais e exclusão (JUVONEN; GRAHAM; SCHUSTER, 2003; BULLOCK, 2002).

Matos e Gonçalves (2019) enfatizam bastante a relação delineada entre a percepção de segurança da escola, o andar com armas e a satisfação com a vida e os comportamentos de bullying. Sendo que

[...] quanto mais os alunos percepcionam a escola como sendo insegura, mais relatam ser vítimas de bullying e mais referem incomodar os colegas; o mesmo padrão é verificado com o porte de armas. Por sua vez, quanto mais insatisfeitos os alunos estão com a sua vida, mais se sentem provocados e mais provocam. Um maior consumo de álcool e de tabaco está associado com uma maior violência sentida e exercida (MATOS; GONÇALVES, 2019, p. 15).

Desta forma, os resultados do estudo dos autores supracitados descrevem-se em linhas práticas de intervenção sobre o problema do bullying, a evidenciar a importância de os alunos identificarem segurança nas escolas, evitar o porte de arma e colaborar para a satisfação dos alunos.

\section{SOBRE O COMBATE AO BULLYING E OS DOCUMENTOS QUE REGEM A EDUCAÇÃO}

A necessidade de os currículos escolares terem uma base comum a nível nacional é um tema que tem gerado discussões há bastante tempo. Além disso, a necessidade de se determinar as reais funções da escola também tem sido foco de diversas pesquisas na literatura da área educacional.

Com a promulgação da Lei oํ 9.394, de 20.12.1996, também conhecida como Lei de Diretrizes e Bases da Educação Nacional (LDB) essa intenção ficou bastante clara. Sobre isso, Saviani $(2016$, p. 28) afirma que "[...] a organização curricular da escola desde a Educação Infantil até o Ensino Médio tem o caráter de uma educação geral comum e universal destinada, portanto, a toda a população". 
Ainda com o objetivo de uma educação comum a todos, após a LDB, os já citados Parâmetros Curriculares Nacionais (BRASIL, 1998) foram lançados e, enquanto a LDB, como legislação, tem como função principal a organização e estruturação da educação no país, os PCNs surgiram com o intuito de fornecer subsídios para a elaboração da proposta curricular no âmbito específico de cada instituição de ensino.

Com um intuito muito semelhante aos do PCN, porém com mais detalhes, a Base Nacional Comum Curricular, estruturada em três ciclos, a saber: Educação Infantil, Ensino Fundamental e Ensino Médio, surge no âmbito educacional a partir do ano de 2017.

Machado e Lockmann (2014) discutem o alargamento das funções da escola na contemporaneidade explicitada pela BNCC, que pode ser definida como "um documento de caráter normativo que define o conjunto orgânico e progressivo de aprendizagem essencial que todos os alunos devem desenvolver ao longo das etapas e modalidades da Educação Básica" (BRASIL, 2017, p. 5).

Ainda de acordo com o que consta na própria BNCC, o objetivo deste documento é corresponder às demandas dos estudantes desta época, preparando-os para o futuro (BRASIL, 2017). Além disso, o documento é

pautado em altas expectativas de aprendizagem, que deve ser acompanhado pela sociedade para que, em regime de colaboração, faça o país avançar [...] de modo que, em regime de colaboração, as mudanças esperadas alcancem cada sala de aula das escolas brasileiras. Somente aí teremos cumprido o compromisso da equidade que a sociedade brasileira espera daqueles que juntos atuam na educação (BRASIL, 2017, p. 5).

Em linhas gerais, a BNCC discute as competências gerais da Educação Básica e, embasada em marcos legais e fundamentos pedagógicos específicos, o documento apresenta uma estrutura curricular para cada um dos três níveis de escolaridade.

Dados tais objetivos e fundamentos, as competências socioemocionais citadas pela BNCC dizem respeito a, dentre outras coisas, saber reconhecer emoções; conhecer as próprias capacidades, fraquezas, personalidade, valores, crenças e motivações; 
compreender a si mesmo e perceber como se é reconhecido pelo outro; saber gerenciar emoções, pensamentos e comportamento; estabelecer metas, motivar-se e alcançar objetivos; apreciar as perspectivas dos outros; compreender normas e saber identificar oportunidades e recursos disponíveis (ABED, 2016).

Além dessas ao estabelecer e manter relações, gerenciar construtivamente problemas comportamentais e saber tomar decisões responsáveis são outros exemplos de competências socioemocionais importantes para o processo de aprendizagem (idem) e são justamente essas competências que fazem da escola uma instituição responsável pela prevenção de ações relacionadas ao bullying em sala de aula.

Ainda segundo Abed (2016), as competências elencadas na BNCC são buscadas por meio das chamadas intervenções universais, isto é, ações direcionadas a todo e qualquer estudante, que objetivam 0 desenvolvimento das competências socioemocionais do estudante, conduzidas por professores em sala de aula.

A autora supracitada ressalta ainda que além do desenvolvimento destas competências, as intervenções universais têm o potencial de melhorar as atitudes, comportamentos e saúde dos estudantes, além de promover o aprendizado acadêmico.

\section{CONSIDERAÇÕES FINAIS}

Buscando investigar a questão do bullying nas escolas brasileiras e suas consequências, o presente trabalho discutiu, a partir de referenciais teóricos da área da Educação, psicologia e dos documentos que regem a educação básica, a função da escola e da família enquanto promotora da formação acadêmica e sua participação na evolução das competências e nos cuidados socioemocionais dos indivíduos.

Assim, lançando-se mão de estratégias metodológicas relacionadas à pesquisa qualitativa interpretativa, de cunho descritivo bibliográfico, foram identificados alguns pontos importantes neste texto, como as situações mais frequentes de bullying sofridos pelos estudantes em sala de aula, a saber: exclusão pelos colegas; piadas; ameaças; agressões físicas, materiais e psicológicas; dentre outras práticas. 
Ao fim das articulações teóricas fica evidente a importância do desenvolvimento das competências socioemocionais no processo de formação dos estudantes, principalmente os da Educação Básica, que são as principais vítimas de bullying nas escolas.

Tal importância se dá por conta do impacto de tais competências no processo de formação cidadã dos alunos, ou seja, para se apropriarem dos conhecimentos acadêmicos e dos conceitos éticos e morais que regem a vivência em sociedade é necessário que os estudantes sejam expostos à práticas e situações que possibilitem o desenvolvimento de habilidades, ou competências, relacionadas à sua atuação na sociedade contemporânea em constante transformação.

Além disso, a instituição familiar também tem uma importante função na prevenção do bullying nas escolas. Sobre isso, Kaloustian (1998) afirma que a instituição familiar é um espaço privilegiado de socialização em que a criança terá suas primeiras práticas de convivência em grupo, aprendendo noções de responsabilidade e civilidade.

Portanto, o desenvolvimento afetivo do sujeito é diretamente influenciado pelas relações familiares, podendo tais relações atingirem positiva ou negativamente o bemestar dos indivíduos.

Especificamente na perspectiva educacional, a família desempenha uma função importante na educação formal e informal. A instituição família, assim como a instituição escolar, tem impacto direto no desenvolvimento cognitivo, cultural, social e emocional da criança, ao mesmo tempo em que é transmissora dos conhecimentos cientificamente aceitos pela sociedade.

\section{REFERÊNCIAIS}

ABED, A. L. Z. O desenvolvimento das habilidades socioemocionais como caminho para a aprendizagem e o sucesso escolar de alunos da educação básica. Construção psicopedagógica, v. 24, n. 25, p. 8-27, 2016. 
ARIÈS, P. História social da criança e da família. 02.ed. Rio de Janeiro: LTC - Livros Técnicos e Científicos, 1981.

AVILÉS MARTÍNEZ, J. M. Bullying: el maltrato entre iguales. Agresores, víctimas y testigos en la escuela. Salamanca: Amarú, 2006.

BRASIL. Lei no 9.394, de 20 de dezembro de 1996. Estabelece as diretrizes e bases da Educação Nacional. Brasília: MEC, 1996.

. Parâmetros Curriculares Nacionais (PCN). Brasília: MEC/SEF, 1998.

. Lei no 13.185, de 6 de novembro de 2015. Institui o Programa de Combate à Intimidação Sistemática (Bullying). Secretaria-Geral. Subchefia para Assuntos Jurídicos, 2015.

. Base Nacional Comum Curricular (BNCC). Educação é a Base. Brasília, MEC/CONSED/UNDIME, 2017.

BULGRAEN, V. C. O papel do professor e sua mediação nos processos de elaboração do conhecimento. Revista Conteúdo, Capivari, v. 1, n. 4, p. 30-38, 2010.

BULLOCK, J. Bullying among children. Childhood Education, 78(3), 130-133, 2002.

BUROCHOVITH, E.; SANTOS, A. A. A. Inventário de Depressão Infantil (CDI): análise dos parâmetros psicométricos. Fractal: Revista de psicologia, v. 20, n. 2, p. 473489, 2008.

CASTRO, C. A. P. Sociologia geral. São Paulo: Atlas, 2000.

CERVI, G. M. Política de gestão escolar na sociedade de controle. Rio de Janeiro: Achiamé, 2013.

COSTA, A. R. Sintomatologia depressiva em crianças numa unidade de saúde do Norte (Doctoral dissertation, Universidade Católica Portuguesa). Recuperado de http://repositorio.ucp.pt/handle/10400.14/8806, 2011. 
DEVECHI, C. P. V.; TREVISAN, A. L. Sobre a proximidade do senso comum das pesquisas qualitativas em educação: positividade ou simples decadência? Revista Brasileira de Educação. Rio de Janeiro, v. 15, n. 43, p. 148-155, 2010.

FANTE, C. Fenômeno bullying: como prevenir a violência nas escolas e educar para a paz (2a. ed.). Campinas: Verus Editora, 2005.

FANTE, C.; PEDRA, J. A. Bullying escolar: perguntas e respostas. Porto Alegre: Artmed, 2008.

FONSECA, M. H. G.; FERREIRA, R. A.; FONSECA, S. G. Prevalência de sintomas depressivos em escolares. Pediatria, 27(4) 113-122, 2005.

GIL, A. C. Métodos e técnicas de pesquisa social. 6. ed. São Paulo: Atlas, 2008.

JUVONEN, J.; GRAHAM, S.; SCHUSTER, M. Bullying Among Young Adolescents: The Strong, the Weak, and the Troubled. Pediatrics, 112(6) 1231-1237, 2003.

KALOUSTIAN, S. Positional cloning of the gene for Nijmegen breakage syndrome. Nature genetics, v. 19, n. 2, p. 179-181, 1998.

LAKATOS, E. M.; MARCONI, M. A. Técnicas de pesquisa. 5. ed. São Paulo: Atlas. 2003.

LÜCK, H. Dimensões da gestão escolar e suas competências. Curitiba: Editora Positivo, p. 47-69, 2009.

MACHADO, R. B.; LOCKMANN, K. Base nacional comum, escola, professor. Revista e-Curriculum, v. 12, n. 3, p. 1591-1613, 2014.

MATOS, M. G.; GONÇALVES, S. M. Pedroso. Bullying nas escolas: comportamentos e percepções. Psicologia, saúde \& doenças, v. 10, n. 1, p. 3-15, 2019.

MOURA, D. R.; CRUZ, A. C. N.; QUEVEDO, L. Á. (2011). Prevalência e características de escolares vítimas de bullying. Jornal de Pediatria, 87 (1), 19-23, 2011. 
SANTAELLA, L. Culturas e artes do pós-humano: da cultura das mídias à cibercultura, São Paulo, Paulus, 2008.

SAVIANI, D. Educação: do senso comum à consciência filosófica. São Paulo: Cortez, 1987.

TENAGLIA, A. M. L. B. Professores com Transtornos Psicológicos e a Ausência de Políticas Públicas. Psicologado - Políticas Públicas, 2018.

TREVISOL, M. T. C.; CAMPOS, C. A. Bullying: verificando a compreensão dos professores sobre o fenômeno no ambiente escolar. Psicologia Escolar e Educacional, SP, volume 20, número 2, págs. 275-283, 2016.

ZIMER, T. T. B. Aprendendo a ensinar matemática nas séries iniciais do ensino fundamental. Tese de Doutorado. Universidade de São Paulo, 2008.

Enviado: Outubro, 2020.

Aprovado: Novembro, 2020. 